4 Carmen M. Fernández-Marchante ${ }^{\mathrm{a}}$, Yeray Asensio ${ }^{\mathrm{a}}$, Luis F. León ${ }^{\mathrm{a}}$, José Villaseñor ${ }^{\mathrm{b}}$, 5 Pablo Cañizares ${ }^{\mathrm{a}}$, Justo Lobato ${ }^{\mathrm{a}}$, Manuel A. Rodrigo ${ }^{\mathrm{a}^{*}}$

$6 \quad{ }^{a}$ Department of Chemical Engineering. Faculty of Chemical Sciences \& Technologies. 7 University of Castilla-La Mancha. Av. Camilo Jose Cela n 12, 13071 Ciudad Real. Spain. 8 bepartment of Chemical Engineering. Research Institute for Chemical and 9 Environmental Technology (ITQUIMA), University of Castilla-La Mancha, 13071,

\section{Thermally-treated algal suspensions as fuel for Microbial}

\section{Fuel Cells}

\section{Ciudad Real, Spain}

\section{Abstract}

Three thermally-treated chlorella vulgaris algal suspensions were fed to twocompartment microbial fuel cells (MFCs) for more than three months and performance was monitored in order to determine whether this type of fuel is suitable for MFC and if the thermal treatment of the algae attains any improvement in the efficiency of the system. The algal suspensions were divided into three portions and conditioned thermally at 25 , 55 and $95^{\circ} \mathrm{C}$, before being introduced in each MFCs. Results obtained by the three MFCs demonstrate that algal suspension is a good fuel for the electrochemical devices and that the temperature conditioning of the fuel influences on the performance of the technology in a different way after long times of operation. Thus, within the operation condition setup, the best operation performance was obtained by the cell fed with algae conditioned at the lowest temperature, the polarization curves demonstrated that performance was improved after long operation times when a higher temperature conditioning was performed. 
* Corresponding author: manuel.rodrigo@uclm.es

\section{Keywords}

Algae; durability; microbial fuel cell; thermal treatment

\section{Introduction}

The search for new energy sources, in replacement of fossil fuels, is one of the main issues facing Humankind in the context of an overpopulated world [1]. Sun is the primary source of energy on Earth and living beings have evolved for hundreds of millenniums in a way that allows to use this energy in the most efficient way.

Photosynthesis is the key to understand life on Earth. In fact, it is the way found by

Nature to produce organic compounds from inorganic species and transform sun energy into profitable energy for living beings [2,3]. Within this context, the production of autotrophic photosynthetic microorganisms and their use as fuel is a positive action for the preservation of our environment and it has been a hot topic in the development of many energy technologies [4-6].

Microbial fuel cells are bioelectrochemical devices that achieve the direct transformation of the chemical energy contained in biodegradable fuels into electricity [7-12]. This is possible because of the action of bioelectrogenic microorganisms, which are capable to oxidize organic matter in the absence of oxygen, harvesting the electrons required for their oxidation and promoting their transport from an anode to a cathode surface, when species susceptible of being reduced are contained in the vicinity of this latter electrode [13].

Recently, the combination of algae and microbial fuel cells has been proposed, although most of the studies are focused on finding and developing a solution to overcome the problems found in MFC technology: they require oxygen in the cathode (because 
oxygen is the cheapest and perhaps the most cost-efficient oxidant for the cathodic reactions). However, aeration is not a cheap process. As photosynthesis produce oxygen by natural processes, it may help to avoid the necessity of mechanical aerators or air diffusion systems. The outstanding results shown in the literature support the use of algae for this application [12,14-15], despite the important weakness which comes from the changing production of oxygen over the day light/dark periods.

Most recently, algae have been studied not only as natural aerator of the cathode compartment but as a possible fuel for MFC. It has been noticed that microorganisms could degrade algae biomass, which is mainly composed by proteins, carbohydrates and lipids [16]. Nevertheless, all those compounds that formed algal biomass are complex substrates for microorganisms, so no great amount of energy has been produced at this moment $[17,18]$.

In the last years, taking into account the advances previously described, self-sustainable MFCs have been developed to generate energy in a renewable, sustainable and efficient way [19]. However, the electric efficiency using this technology is still low due to the low biodegradability of the algal biomass. Because of this weakness, the use of toxic mediators for electron shuttling [20] and the use of expensive catalysts is recurrent, limiting the use of this self-sufficient MFC for real applications. As it can be seen, fuel is one of the most important inputs to be considered in the evaluation of sustainable MFCs. Improving the biodegradability of the fuel, the use of artificial mediators and catalysts would not be necessary, decreasing the operational costs of these bio devices. Light has been a extensively studied parameter on algal growth and composition [2123], but temperature, which could be applied using the heat produced by sunlight, is a key factor producing the biomass degradation into smaller molecules that could be better digested by microorganism cultures. 
Taking into account this background, the goal of this work is to evaluate the advantages and drawbacks of a thermal pre-treatment on the performance of MFC. To do this, a bioreactor is operated to produce daily a raw algae suspension from which three different fuels are prepared by heating these suspensions for 24 hours at 25, 55 and 95 ${ }^{\circ} \mathrm{C}$. Each different pretreated algal suspension was fed to a different MFC for a long period of time (100-days) in which main operation parameters as well as polarization curves are monitored in order to know if thermally-pretreated algae can be used as fuel in long-term operations, and which is the optimum pretreatment condition.

\section{Materials and methods}

\subsection{Algae production bioreactor.}

Chlorella Vulgaris, purchased from Spanish bank of algae (Spain), was used as initial seed, and a 2 liter tank was used to produce the raw alga suspension. This bioreactor was operated during all the experiment in semi continuous mode, being fed once a day with $117 \mathrm{~mL}$ of Bold's basal medium which compositions is shown in Table $1[24]$.

Table 1. Bold's basal medium for "Chlorella vulgaris".

\begin{tabular}{|c|c|}
\hline Component & Bolds's basal medium $\left(\mathrm{g} \mathrm{L}^{-1}\right)$ \\
\hline $\mathrm{NaCl}$ & $2.500 \times 10^{-2}$ \\
\hline $\mathrm{MgSO}_{4} \cdot 7 \mathrm{H}_{2} \mathrm{O}$ & $7.500 \times 10^{-2}$ \\
\hline $\mathrm{CaCl}_{2} \cdot 2 \mathrm{H}_{2} \mathrm{O}$ & $2.500 \times 10^{-2}$ \\
\hline $\mathrm{EDTA}$ & $5.000 \times 10^{-2}$ \\
\hline $\mathrm{FeSO}_{4} \cdot 7 \mathrm{H}_{2} \mathrm{O}$ & $5.000 \times 10^{-3}$ \\
\hline
\end{tabular}




\begin{tabular}{|c|c|}
\hline $\mathrm{H}_{3} \mathrm{BO}_{3}$ & $1.140 \times 10^{-2}$ \\
\hline $\mathrm{ZnSO}_{4} \cdot 7 \mathrm{H}_{2} \mathrm{O}$ & $1.412 \times 10^{-3}$ \\
\hline $\mathrm{MnSO}_{4} \cdot 4 \mathrm{H}_{2} \mathrm{O}$ & $2.320 \times 10^{-4}$ \\
\hline $\mathrm{CuSO}_{4} \cdot 5 \mathrm{H}_{2} \mathrm{O}$ & $2.520 \times 10^{-4}$ \\
\hline $\mathrm{NaNO}_{3}$ & $2.500 \times 10^{-1}$ \\
\hline $\mathrm{K}_{2} \mathrm{HPO}_{4}$ & $7.500 \times 10^{-2}$ \\
\hline $\mathrm{KH}_{2} \mathrm{PO}_{4}$ & $1.750 \times 10^{-1}$ \\
\hline $\mathrm{KOH}$ & $3.100 \times 10^{-2}$ \\
\hline
\end{tabular}

95

96

\subsection{Microbial fuel cell.}

Three two-compartment microbial fuel cell equipped with carbon felt electrodes and with an ionic exchange membrane to separate anode and cathode compartments is used in this work. Details of this type of cell can be found elsewhere [25].

Analytical techniques. COD and nitrogen were measured using a Velp ECO-16 digester and a Pharo 100 Merck spectrophotometer analyzer. 
Polarization curves were performed periodically and were obtained by varying the external resistance in the electric circuit and measuring the output voltage of the three MFCs [26].

\subsection{Experimental procedure}

Activated sludge from wastewater treatment plant (Ciudad Real, Spain) was used as inoculum for the anodic compartment. The activated sludge was preconcentrated by a decantation process and placed in the anodic compartment in a 1:2 ratio without aeration to favor the formation of an anaerobic mixed culture of microorganisms. During these days, no synthetic wastewater was added to the microorganisms culture. The MFCs were fed once a day. Nevertheless, the operation process can be considered as a semi-continuous one during long periods of time.

Hydraulic retention time (HRT) was the same for all devices (3.16 d). The three MFCs fed with the alga suspension treated at $25^{\circ} \mathrm{C}(\mathrm{MFC} 1), 55^{\circ} \mathrm{C}(\mathrm{MFC} 2)$ and $95^{\circ} \mathrm{C}(\mathrm{MFC} 3)$, respectively, were operated at the same time to avoid the change of input parameters that could affect the electricity generation.

\section{Results and discussion}

In this work, to evaluate the use of thermally treated algal suspensions as fuel for MFC, three tests were carried out. In each test, an MFC was fed with a different suspension of algae obtained in the same bioreactor, although they were thermally treated at 25 (MFC1), 55 (MFC2) or $95{ }^{\circ} \mathrm{C}(\mathrm{MFC} 3)$ for 24.0 hours and, then, left to stabilize at room temperature before being fed to the MFC. The tests were carried out simultaneously and the remaining operation parameters of the three MFCs (operation temperature, 
135 external resistance, flowrates, volume of the reservoir tank, electrode materials, etc.)

136 were kept within the same values, so that differences are expected to be caused only by

137 the characteristic of the fuel fed.

138 Figure 1 shows the concentration of algae obtained from the algae production bioreactor

139 over the 80-day duration of the tests. These algal suspensions were later used (after

140 heating conditioning) as fuel for the three MFCs tested in this work. Comparing the

141 values shown in Figure 1, only in terms of macroscopic quality of algae (total

142 suspended solid concentration and chlorophyll), the production seems to be at nearly

143 steady state conditions during the complete period of study. This stationarity was also

144 confirmed in the measurement of the total COD (not shown) of the algal suspension.

145 However, this information contrasts with the next Figures. Figures concerning the

146 nitrogen may indicate significant changes in the composition of this suspension, in

147 particular during the first 40-50 days. Once the daily production of the reactor was

148 obtained, it was divided into three different portions, which underwent the different

149 thermal treatment to be conditioned as fuel the three microbial fuel cells studied in this

150 work. 


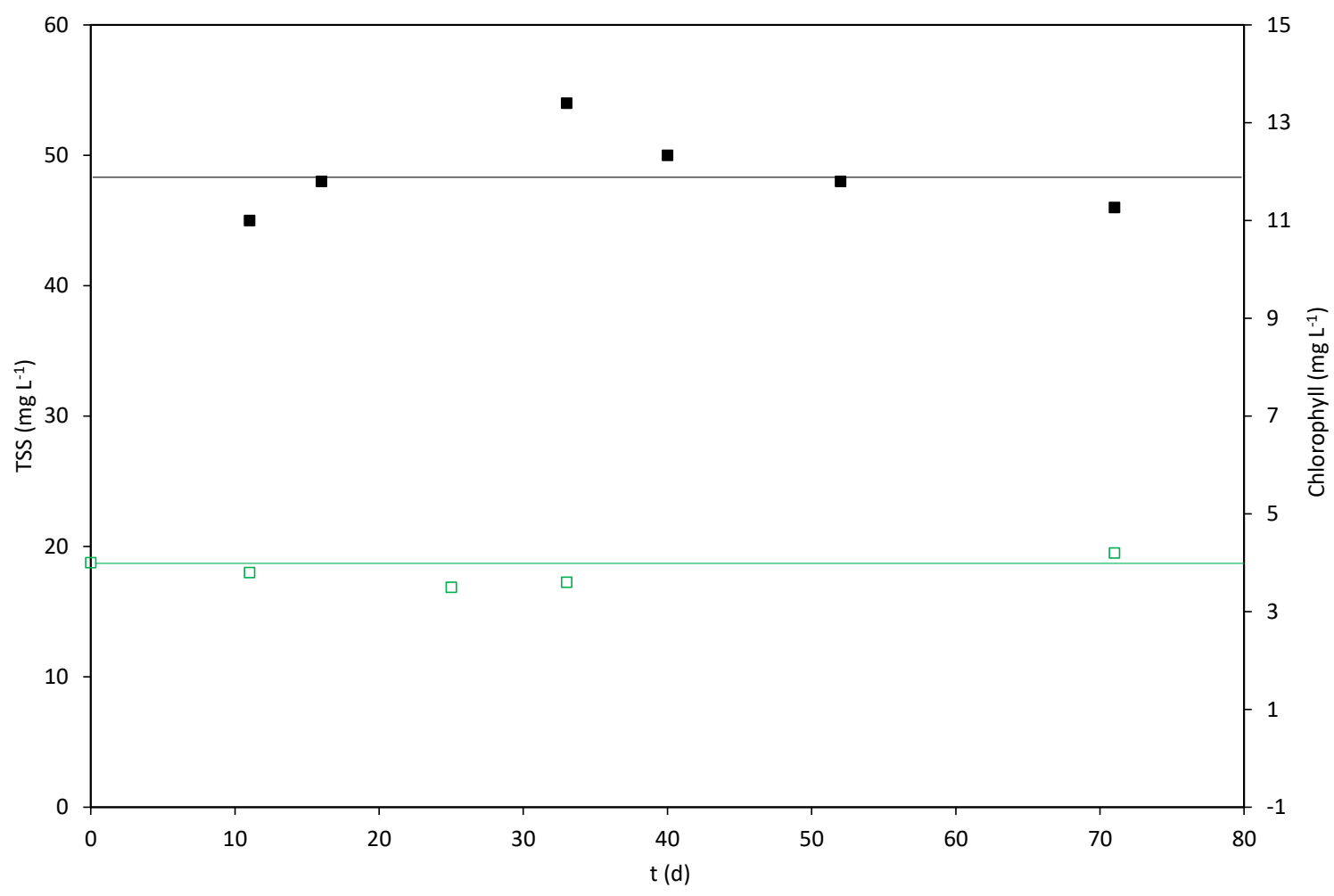

152

153

154

Fig. 1. Changes in the total suspended solid (TSS) and chlorophyll concentrations of the alga suspension produced by the alga production bioreactor. (ロ) TSS (mg L $\mathrm{L}^{-1}$ ), ( $\square$ ) Chlorophyll (mg L-1)

Figure 2 compares the influent and effluent COD in the MFCs during the 90-day long test and the output total nitrogen (TN) in the MFCs. The first important observation is that influent COD is not the same. This is important, because only one raw algal suspension was produced, using the same bioreactor and the only difference between the different fuels is the thermal treatment that this suspension has undergone.

According to results, temperature seems to have a positive effect on the resulting COD concentration and, thus, MFC3 shows an average COD of $846.0 \pm 43.1 \mathrm{mg} \mathrm{O}_{2} \mathrm{dm}^{-3}$, while MFC2 exhibits a value of $748.3 \pm 35.9 \mathrm{mg} \mathrm{O}_{2} \mathrm{dm}^{-3}$ (11\% lower with respect to the previous one) and MFC1 a value of $736.0 \pm 36.4 \mathrm{mg} \mathrm{O}_{2} \mathrm{dm}^{-3}$ (13\% lower than the value obtained at $\left.95^{\circ} \mathrm{C}\right)$. Initially, thermal treatment was not expected to affect the COD, which quantified only the chemically oxidizable species contained in the algal 

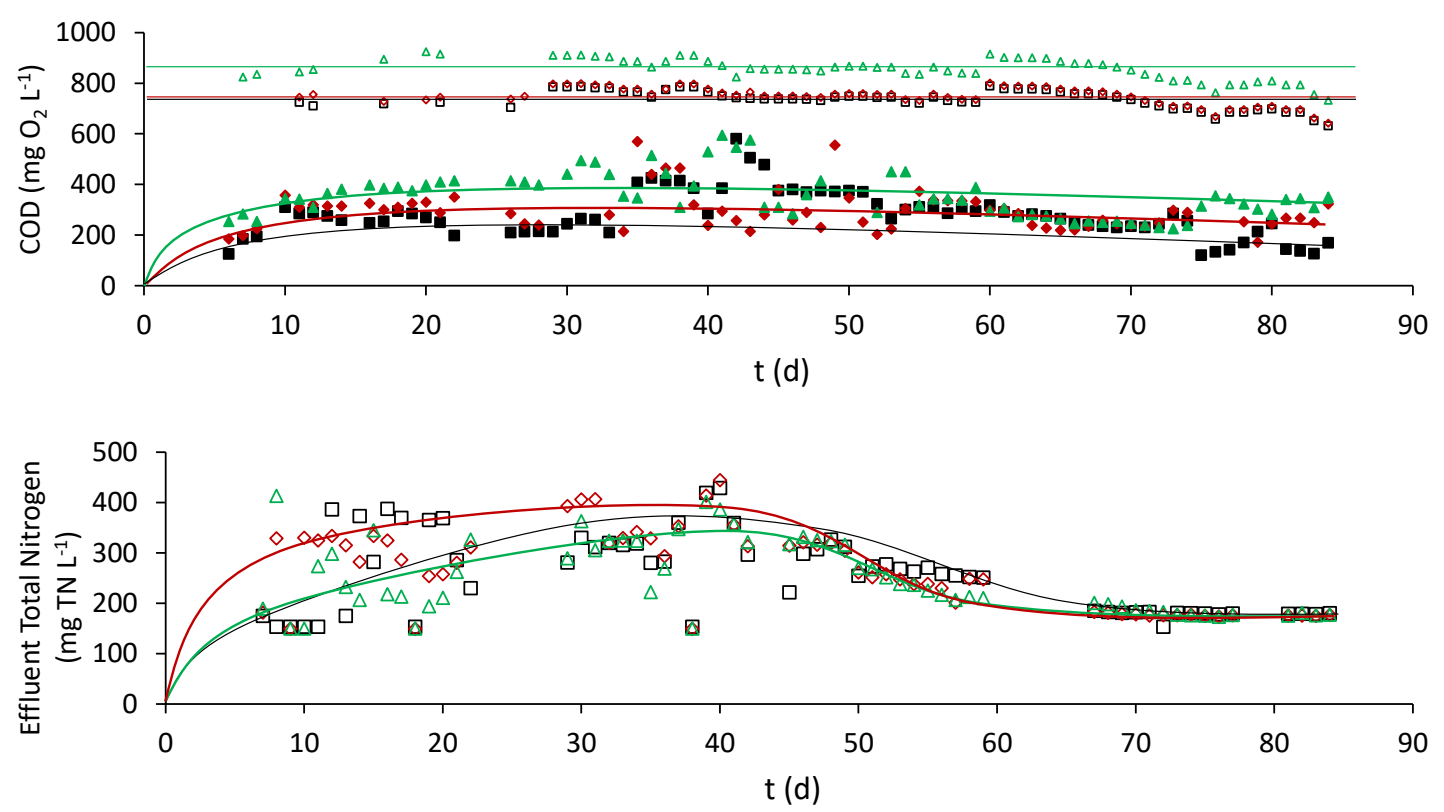

173

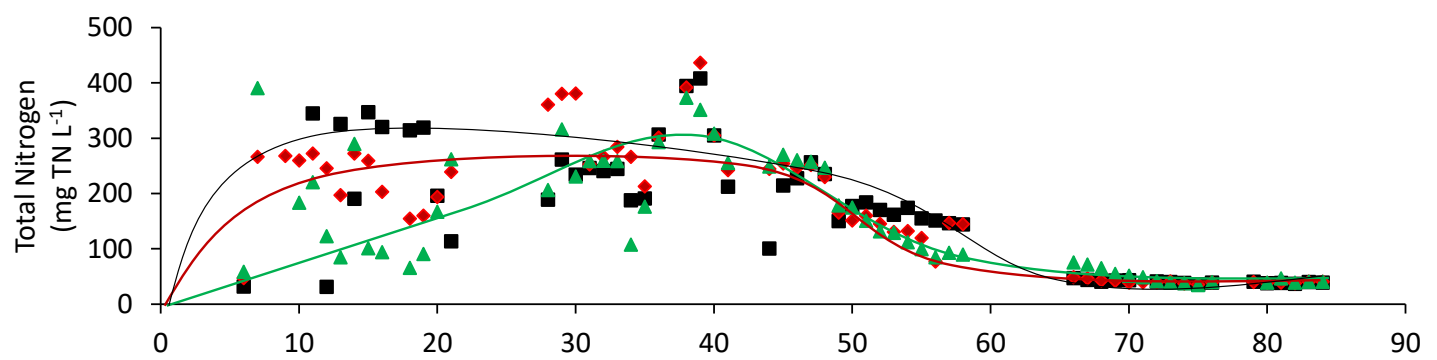

Fig. 2. Changes in the influent (empty symbols) and effluent (full symbols) COD (a) and Total Nitrogen $(\mathrm{TN})(\mathrm{b}, \mathrm{c})$ during the operation test in which MFCs were fed with algae biomass thermally treated at: $(\square, \boldsymbol{\square}) 25^{\circ} \mathrm{C},(\diamond, \diamond) 55^{\circ} \mathrm{C},(\triangle, \Delta) 95{ }^{\circ} \mathrm{C}$. This Figure is intended for view in colour

The other important information that can be drawn from the Figure 2 is the removal of COD attainable by the MFC. As it can be seen, the lowest COD in the effluent are observed for MFC1, with an average value of $278.9 \pm 90.7 \mathrm{mg} \mathrm{O}_{2} \mathrm{dm}^{-3}$, while the highest 
values are achieved by MFC3, which shows an average value of $353.7 \pm 85.9 \mathrm{mg} \mathrm{O}_{2} \mathrm{dm}^{-}$

${ }^{3}$. The effluent of MFC2 shows an intermediate value of organic load in the outlet, 293.2 $\pm 76.6 \mathrm{mg} \mathrm{O}_{2} \mathrm{dm}^{-3}$.

One further important observation that can be obtained from the results shown is related to the deviation of data. It is more than double in the effluent than in the influent, clearly pointing out the great variability introduced on results by the complex processes happening on the anodic compartment of the MFCs.

The other important parameter of the algal suspension is the nitrogen content and the relevant information regarding this parameter is shown in Figure 2. In this case, the average values measured in the fuel during the complete tests were $233.0 \pm 81.2$, $239.1 \pm 84.1$, and $225.5 \pm 75.6 \mathrm{mg} \mathrm{N} \mathrm{dm}^{-3}$, respectively, for the fuels treated at 25,55 and $95^{\circ} \mathrm{C}$. Here, the differences between fuels are lower and almost no significant from a statistical point of view, pointing out that the thermal treatment did not affect this parameter. However, as it can be seen in the figure, there is a changing quality of the fuel. These changes have to be associated to the quality of the raw algal suspension produced in the bioreactor. Onwards from day 40 these changes stabilize in lower values and with much lower deviations, with values of $172.8 \pm 11.6,170.2 \pm 10.5$ and $172.8 \pm 15.8 \mathrm{mg} \mathrm{N} \mathrm{dm}^{-3}$, respectively, for the fuels pretreated at 25,55 and $95^{\circ} \mathrm{C}$.

Differences in this second period are even less significant from the statistical viewpoint. It is important to point out that these changes in the nitrogen concentration are related neither to the changes observed in the COD of the influent nor to the external aspect of the raw algal culture and should be understood in terms of the stabilization in the consumption of nutrients in the algae production bioreactor.

Regarding the output values, they are also shown in Figure 2. As observed, for the starting days, the time-course is not as stationary as in the case of COD. This shows a 
209

210

211

very high dispersion, but then, onwards from day 40 there is a clear trend of stabilization, with a reduction to values slightly over $40 \mathrm{mg} \mathrm{N} \mathrm{dm}^{-3}$.

With these values, and by applying mass balance, the COD and nitrogen consumption rate of each MFC can be obtained. The values calculated are shown in Figure 3.
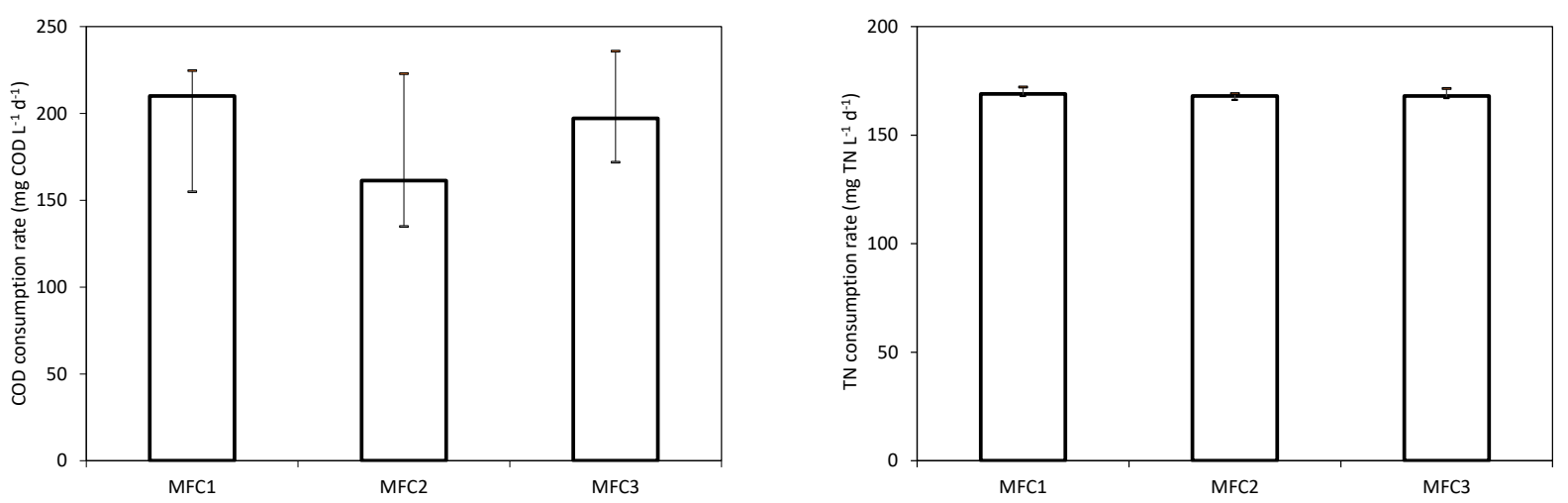

Fig. 3. COD and nitrogen consumption rate achieved in the steady state in the three MFC fed with different conditioned algae suspensions.

As it can be observed, differences are very small and just a slight improvement can be observed in the case of MFC1. Thus, nitrogen consumption rates from day 60 vary in the same fashion that COD consumption rates and results reveal a very important observation: the relationship between both rates is kept almost constant in the three cells: $0.141,0.137$ and 0.140 , respectively for the fuels obtained with a thermal treatment at 25,55 and $95^{\circ} \mathrm{C}$. This ratio matches very well with the value reported in the literature for the nitrogen content of biomass.

Current density produced by the three cells is compared in Figure 4. At this point, it is important to remember that our MFCs are fed only once a day and hence, over the day, there are COD, nitrogen and current density profiles. For the sake of comparison, the profiles of current density of three selected days are shown in Figure 5, where it is observed how after the fuel feeding procedure the current increases and, then, it 
231 decreases continuously until the following day. This motivates the large variation range

232 observed each day with respect to the average conditions. On the other hand, in

233 comparing the three current vs time plots, it can be seen that the three cells underwent

234 the same types of changes in the electricity production. This production is almost nil

235 during the startup and then there is an exponential increase up to a first pseudo-

236 stationary value which later decrease slightly to the final value in which the current

237 produced is stabilized. Differences in the production of electricity are not as high as the

similar variation of the COD in the anode side.
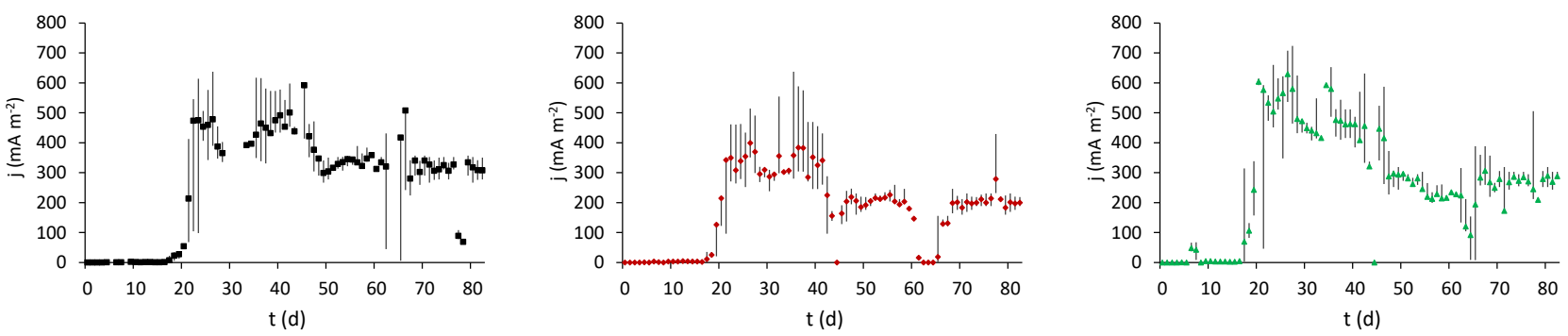

240

Fig. 4. Daily current density and deviations between the maximum and minimum daily values during the operation tests in which MFCs were fed with algae biomass thermally treated at: $(\boldsymbol{\square}) 25^{\circ} \mathrm{C},(\diamond) 55^{\circ} \mathrm{C},(\Delta) 95^{\circ} \mathrm{C}$. This figure is intended for view in colour.

a)

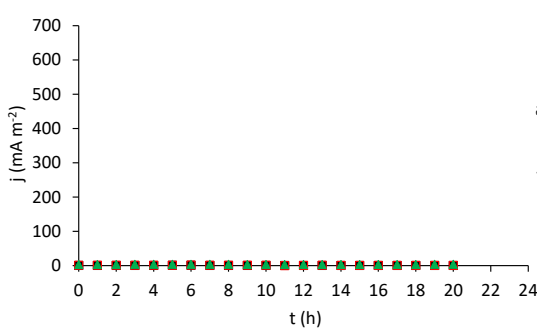

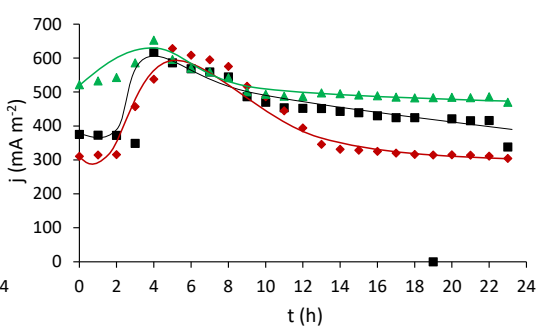

c)

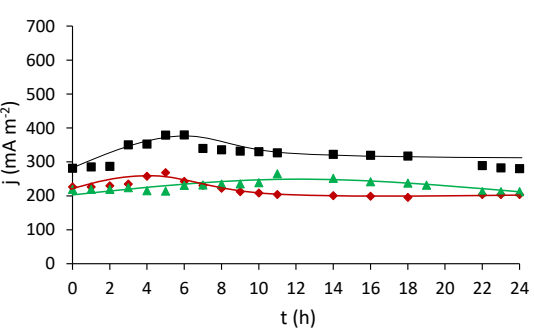

247 Fig. 5. Daily current density profiles obtained at day $20^{\text {th }}$ (part a, latency), $35^{\text {th }}$ (part b, 248 exponential growth) and $55^{\text {th }}$ (part c, stationary) of operation. ( $\left.\mathbf{\square}\right) 25^{\circ} \mathrm{C},(\Delta) 55^{\circ} \mathrm{C},(\Delta)$ $24995^{\circ} \mathrm{C}$. 
251 More information about the production of electricity is given by the polarization curves,

252 because these curves do not inform only about the performance of the MFC at the

253 particular conditions used but they also give some information about their potential

254 performance at other different operation conditions, which may be of interest for

255 potential applications of the technology. At this point, it is important to bear in mind

256 that an MFC can perform better than other in a range of operation parameters and worse

257 in another different range because within the full operation range of MFC, three

258 different mechanisms can limit their performance: activation, ohmic resistance and mass

259 transfer. These mechanisms can affect performance in different ways. In fact, in most

260 MFCs only two regions can be clearly observed because of the effect of the large ohmic

261 resistances associated typically to the experimental devices, which mask the mass

262 transfer losses region. The first mechanism is the most strongly related to the fuel used

263 and the second is more associated to the mechanical manufacturing of the cell (current

264 feeders) and to the characteristics of the materials involved. That can only provide

265 information about the fuel for those with very different ionic conductivity, which it is

266 not the case here. Because of the low concentrations of fuel, and the high ohmic

267 resistances of the MFCs, mass transfer does not use to be an important factor to be

268 considered in order to evaluate the influence of the fuel, although initially it could be

269 expected to be lower for a highly concentrated fuel. As in this case differences in the

270 COD are very narrow, no appreciable effect is expected.

271 Taking into account this information, several of the polarization curves recorded over

272 the tests and changes in the three characterizing parameters of these curves are shown in

273 Figure 6. 

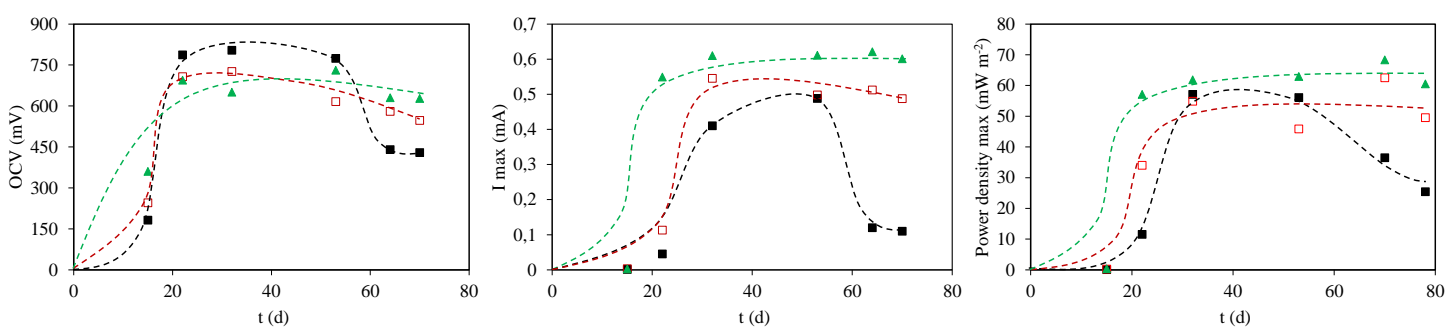

Fig. 6. OCV, maximum currents and maximum power densities achieved during the different polarization curves carried out in this work in which MFC were fed with algae biomass thermally treated at: $(\square) 25^{\circ} \mathrm{C},(\diamond) 55^{\circ} \mathrm{C},(\Delta) 95^{\circ} \mathrm{C}$.

Regarding characterization parameters that can be obtained from the polarization curves, clearly the OCV is higher in the case of feeding the fuel up to day $40-50^{\text {th }}$ and from that moment a very important decrease is observed. As shown, influent COD did not change appreciably during the 90-day tests. On the contrary, nitrogen behavior changed abruptly from that moment. This change may be reflected on the OCV, indicating that before the stabilization of the nitrogen concentration the algal suspension treated at $25^{\circ} \mathrm{C}$ performed better as fuel. Since then, the reduction in the nitrogen content reverses and the fuel conditioned at $95^{\circ} \mathrm{C}$ is the best option.

The maximum intensity is associated to the internal resistance (slope of the decay) when no large activation losses are present. Besides, the initial value of the OCV is similar, as it is the case in the three tests shown. For this reason, the decrease in the maximum intensity value of $\mathrm{MFC}_{1}$ has to be explained in terms of the higher decay slope observed, which, in turn, might be related to the fouling of the membrane or the electrodes. Obviously, this fouling is smaller in the case of the algae fuel conditioned at 55 and at $95^{\circ} \mathrm{C}$, perhaps because of the more important hydrolysis in these latter cases. Regarding the maximum power, during normal operation, the power produced by the MFC fed with the fuel conditioned at 25,55 and $95{ }^{\circ} \mathrm{C}$ was $8.04,3.42$ and $6.55 \mathrm{~mW} \mathrm{~cm}^{-}$ ${ }^{2}$ respectively and they were obtained at cell voltages of $26.1,17.9$ and $23.6 \mathrm{mV}$. These values are much smaller than the optimal power densities $40-60 \mathrm{~mW} \mathrm{~m}^{-2}$ that are 
298

299

300

301

302

303

304

305

306

307

308

309

310

311

312

313

314

315

316

317

318

319

320

321

322

obtained operating the MFC with cell voltages one log-unit above. Thus, to illustrate this point, in $32^{\text {th }}$ day the optimum conditions of the $\mathrm{MFC}_{1}$ (fed with the fuel conditioned at $\left.25^{\circ}\right)$ were $57.06 \mathrm{~mW} \mathrm{~m}^{-2}(220 \mathrm{mV}), \mathrm{MFC}_{2}$ (fuel conditioned at $55^{\circ} \mathrm{C}$ ) were $54.86 \mathrm{~mW} \mathrm{~m}^{-2}\left(143 \mathrm{mV}\right.$ ) and for $\mathrm{MFC}_{3}$ (fuel conditioned at $95^{\circ} \mathrm{C}$ ) were $61.80 \mathrm{~mW}$ $\mathrm{m}^{-2}(155 \mathrm{mV})$. In the $70^{\text {th }}$ day, after the increase in the resistance of the MFC1 caused by fouling, these values shifted to $36.45 \mathrm{~mW} \mathrm{~m}^{-2}(348 \mathrm{mV}), 68.34 \mathrm{~mW} \mathrm{~m}^{-2}(163 \mathrm{mV})$ and $72.50 \mathrm{~mW} \mathrm{~m}^{-2}(205 \mathrm{mV})$, in which the clear degradation of the $\mathrm{MFC}_{1}$, probably associated to the less hydrolyzed alga suspension fed, can be clearly observed. Hence, despite the MFC fed with a fuel pre-processed at $25^{\circ} \mathrm{C}$ performs much better than the other two fuel cells at the operation conditions fixed, the best global performance and the most potential applications are found for the cell fed with an algal culture treated at a higher temperature, because of the higher hydrolysis of the feeding suspension, which contributes to minimize the effects of fouling.

\section{Conclusions}

The following conclusions can be drawn:

- In feeding the MFC with thermally treated algal suspensions, electricity production develops in less than 20 days and reaches almost stationary conditions. No addition of further nutrients was required.

- Thermal treatment influences on the characteristics of the algal suspension as a fuel. The higher the temperature, the higher is the COD measured. But it has not influence on the nitrogen content measured.

- The suspensions of algae treated at the lowest temperature performed the best at the beginning but later deteriorated rapidly because of the greater fouling of the electrodes and membrane surfaces. 


\section{Acknowledgements}

Financial support from Spanish Ministry of Economy and Competitiveness (MINECO)

through project CTQ2013-49748-EXP (Explora Program) is gratefully acknowledged.

\section{References}

[1] S. Bebelis, K. Bouzek , A. Cornell, M.G.S. Ferreira, G. H. Kelsall, F. Lapicque, development of electrochemical engineering, Chem Eng Res Des 91 (10) (2013) 1998-2020

[2] H.X. Chang, Q. Fu, Y. Huang, A. Xia, Q. Liao, X. Zhu, Y.P. Zheng, C. H. Sun, An annular photobioreactor with ion-exchange-membrane for non-touch microalgae cultivation with wastewater, Bioresour Technol 219 (2016) 668-676

[3] R.M. Schwartz, M.O. Dayhoff, Origins of prokaryotes, eukaryotes, mitochondria, and chloroplasts, Science 199 (4327) (1978) 395-403

[4] A.R. Sirajunnisa, D. Surendhiran, Algae - A quintessential and positive resource of bioethanol production: A comprehensive review, Renewable and Sustainable Energy Reviews 66 (2016) 248-267

[5] P. Ayala-Parra, R. Sierra-Alvarez, J.A. Field, Algae as an electron donor promoting sulfate reduction for the bioremediation of acid rock drainage, $\mathrm{J}$ Hazard Mater 317 (2016) 335-343

[6] K. Kumar, S. Ghosh, I. Angelidaki, S.L. Holdt, D.B. Karakashev, M.A. Morales, D. Das, Recent developments on biofuels production from microalgae and macroalgae, Renewable and Sustainable Energy Reviews 65 (2016) 235-249

347 [7] F.J. Hernández-Fernández, A. Pérez De Los Ríos, M.J. Salar-García, V.M.Ortiz- 
Martínez, L.J. Lozano-Blanco, C. Godínez, F. Tomás-Alonso, J. QuesadaMedina, Recent progress and perspectives in microbial fuel cells for bioenergy generation and wastewater treatment, Fuel Process Technol 138 (2015) 284-297

[8] X. Chen, D. Cui, X. Wang, W. Li, (2015) Porous carbon with defined pore size as anode of microbial fuel cell. Biosens Bioelectron 69:135-141

[9] M. Rosenbaum, Z. He, L.T. Angenent, Light energy to bioelectricity: Photosynthetic microbial fuel cells, Current Opinion in Biotechnology 348 (2010) 259-264

[10] Q. Zhao, R. Li,M. Ji, Z.T. Ren, Organic content influences sediment microbial fuel cell performance and community structure, Bioresour Technol 220 (2016) $549-556$

[11] B.E. Logan, B. Hamelers, R. Rozendal, U. Schröder, J. Keller, S. Freguia, P. Aelterman, W. Verstraete, K. Rabaey, Microbial fuel cells: Methodology and technology, Environmental Science and Technology 40(17) (2006) 5181-5192

[12] J. Lobato, A. González del Campo, F.J. Fernández, P. Cañizares, M.A. Rodrigo, Lagooning microbial fuel cells: A first approach by coupling electricityproducing microorganisms and algae, Appl Energy 110 (2013) 220-226

[13] K.H. Mohammadi, K.Y. Cheng, R, Sarukkalige, A.H. Kaksonen, A.S. Kayaalp, M.P. Ginige, A bio-anodic filter facilitated entrapment, decomposition and in situ oxidation of algal biomass in wastewater effluent, Bioresour Technol. 216 (2016) 529-536

[14] X.A. Walter, J. Greenman, I.A. Ieropoulos, Oxygenic phototrophic biofilms for improved cathode performance in microbial fuel cells, Algal Res 2 (3) (2013) $183-187$

[15] Q. Hou, C. Nie, H. Pei, W. Hu, L. Jiang, Z. Yang, The effect of algae species on 
the bioelectricity and biodiesel generation through open-air cathode microbial fuel cell with kitchen waste anaerobically digested effluent as substrate. Bioresour Technol 218 (2016) 902-908

[16] S.B. Velasquez-Orta, T.P. Curtis, B.E. Logan, Energy from algae using microbial fuel cells, Biotechnol Bioeng 103 (6) (2009) 1068-1076

[17] A.M. Lakaniemi, O.H. Tuovinen, J.A. Puhakka, Anaerobic conversion of microalgal biomass to sustainable energy carriers - A review, Bioresour Techno 135 (2013) 222-231

[18] C.C Fu, T.C. Hung, W.T. Wu, T.C. Wen, C.H. Su, Current and voltage responses in instant photosynthetic microbial cells with Spirulina platensis, Biochem Eng J $52(2-3)(2010) \quad 175-180$

[19] D.P.B.T.B. Strik, H. Terlouw, H.V.M. Hamelers, C.J.N. Buisman, Renewable sustainable biocatalyzed electricity production in a photosynthetic algal microbial fuel cell (PAMFC), Appl Microbiol Biotechnol 81(4) (2008) 659-668

[20] B.E. Logan, Simultaneous wastewater treatment and biological electricity generation. Water Sci Technol 52 (1-2) (2005) 31-37

[21] P. Chiranjeevi, S.V. Mohan, Critical parametric influence on microalgae cultivation towards maximizing biomass growth with simultaneous lipid productivity, Renew Energy 98 (2016) 64-71

[22] L. Jiang, Y. Ji, W. Hu, H. Pei, C. Nie, G. Ma, M. Song, Adjusting irradiance to enhance growth and lipid production of Chlorella vulgaris cultivated with monosodium glutamate wastewater, J Photochem Photobiol B Biol 162(2016) $619-624$

[23] S. Jazzar, N.Berrejeb, C. Messaoud, M.N. Marzouki, I. Smaali, Growth Parameters, Photosynthetic Performance, and Biochemical Characterization of 
409

Newly Isolated Green Microalgae in Response to Culture Condition Variations, Appl Biochem Biotechnol 179 (7) (2016) 1290-1308

[24] R. Sharma, G.P.L. Singh, K. Vijendra, Comparison of different media formulations on growth, morphology and chlorophyll content of green alga, Chlorella vulgaris, Int J Pharma Bio Sci 2 (2) (2011) 509-516

[25] A. Raschitor, G. Soreanu, C.M. Fernandez-Marchante, J. Lobato, P. Cañizares, I. Cretescu, M.A. Rodrigo, Bioelectro-Claus processes using MFC technology: Influence of co-substrate. Bioresour Technol 189 (2015) 94-98

[26] E.D. Penteado, C.M. Fernandez-Marchante, M. Zaiat, P. Cañizares, E.R. Gonzalez, M.A. Rodrigo, Influence of sludge age on the performance of MFC treating winery wastewater, Chemosphere 151 (2016)163-170 